\title{
Association between Femoral Stem Positioning and Functional Outcome in Hemiarthroplasty of Hip Joint
}

\author{
Rohan Bhimani ${ }^{1 *}$, Preeti Singh ${ }^{2}$ and Fardeen Bhimani ${ }^{3}$ \\ ${ }^{1}$ Department of Orthopaedics, Hinduja Healthcare Surgicals, India \\ ${ }^{2}$ Department of Orthopaedics, Osmania General Hospital, India \\ ${ }^{3}$ Department of Orthopaedics, Bharati Hospital, India
}

Submission: May 04, 2018; Published: May 17, 2018

*Corresponding author: Rohan A Bhimani, Department of Orthopaedics, Hinduja Healthcare Surgicals, $11^{\text {th }}$ Road, Khar (West), Mumbai-400052, India, Tel: +918552851122; Email: dr.rohanbhimani@gmail.com

\begin{abstract}
Introduction: Intracapsular neck of femur fractures are common in geriatric population. Women are more predisposed to these fractures in comparison to men. Hemiarthroplasty is the most common treatment for displaced fractures of the femoral neck in the elderly. The aim of this study was to evaluate the effect of varus and valgus position of femoral stem and its comparative functional outcome in bipolar hemiarthroplasty. In addition, the study also helps to determine comparative range of motion between valgus and varus group.
\end{abstract}

Material and Methods: This is a prospective study in which 32 consecutives cases of intracapsular fracture neck of femur, between the age of 50-90 years were subjected to bipolar hemiarthroplasty and followed up for 6 months. All patients were examined radiologically and clinically post-operatively for functional outcome with Harrsi Hip score. Statistical data analysis was conducted using SPSS 18.0. Student $t$ test and chi square test were used to compare the level of significance with $\mathrm{p}$ value $\leq 0.05$ considered as statistically significant.

Result: The mean range of motion did not vary significantly between valgus and varus groups. In addition, the mean Harris Hip Score also did not show any significant difference between valgus and varus groups. The average Harris Hip Score was 86.5. Furthermore, in both the groups, majority of the patients showed Excellent outcome. Overall, we had excellent results in 18 (56.25\%), good in 11 (34.4\%) and fair in 3 (9.4\%) patients.

Conclusion: Hemiarthroplasty using uncemented bipolar prosthesis is a good procedure for the elderly and provides early rehabilitation There is no statistical difference between Harris hip score of varus and valgus group of femoral stem positioning.

Keywords: Hemiarthroplasty; Bipolar prosthesis; Neck of femur fracture; Hip joint

\section{Introduction}

The incidence of femoral neck fractures, one of the most common traumatic injuries in elderly patients increases with age $[1,2]$. Assuming that the age-related incidence will increase by only $1 \%$ per annum, the number of hip fractures in the world will reach 8.2 million in 2050. The femoral neck fractures are rare among young people which is only $2 \%$ in patients under 50 years of age. Eighty percent of hip fractures occur in women and $90 \%$ in people older than 50 years [2].Various modalities of treatment are employed, but the problem remains an enigma unsolved until today [3]. Prolonged immobilization in elderly will jeopardize the life span of the patient and further complicate the problem. Thus, complete immobilization to achieve a bony union is nearly obsolete and surgeons resort to early ambulatory procedures by surgery.

The blood supply to the neck and head of the femur is extensive, intricate and complicated [4]. Fracture healing mainly depends on the good blood supply. As the blood supply to the neck is frequently damaged, it jeopardizes the treatment of these fractures and thus the healing process. Fractures of neck of femur have always presented as a great challenge to orthopaedic surgeons. They are often associated with co-morbid conditions like hypertension, cardiac problems, diabetes and dementia. This combined with prolonged immobilization due to fractures leads to increased morbidity and mortality [5]. Hence, early mobilization after hemiarthroplasty is essential in intracapsular neck of femur fractures. Undisplaced intracapsular hip fracture are almost invariably treated with internal fixation [6]. However; most of the fractures are displaced and occur predominantly in elderly female patients. Bones are osteoporotic in elderly patients. Despite the ubiquitous nature of these fractures, there is still a surprising degree of variation in treatment $[5,6]$.

Hemiarthroplasty is the mostcommon treatmentfor displaced fractures of the femoral neck in the elderly and is associated with better functional outcome and fewer reoperations than internal 
fixation [6]. A large number of prostheses have been used with or without cement but no definite conclusions have been made, regarding which type of arthroplasty is preferred [6,7]. There is some evidence of inferior short-term results, with decreased mobility and more pain when using an uncemented implant and concerns regarding fixation problems with uncemented stems in osteoporotic bone have been raised [6,7]. The bonding between prosthesis and femur is dependent upon bony in growth when cement is not used whereas in cemented prosthesis, cement forms a solid bond between prosthesis and femoral bone. The advantages of cementing are a less post-operative mid-thigh pain, as the prosthesis is firmly fixed within the femur and a reduced long-term revision rate from loosening of the prosthesis. Major side effects of cement are cardiac arrhythmias and cardiorespiratory collapse, which occasionally occur on application. These potentially fatal complications are caused either by embolism from marrow contents forced into the circulation or by a direct toxic effect of the cement. During insertion, femoral stem can go into varus or valgus position. The purpose of this study is to evaluate the effect of varus and valgus position of femoral stem and its comparative functional outcome in bipolar hemiarthroplasty. In addition, the study also helps to determine comparative range of motion between valgus and varus group.

\section{Materials and Methods}

Between August 2016 and July 2017, 32 patients with intracapsular fracture neck femur in the age group of 50-90 years were consecutively selected. We prospectively gathered their data. The exclusion criteria included patients managed conservatively for other medical reasons and those with neurovascular compromise. There were 16 males and 16 females included in the study. There were 16 patients under each category of Valgus and Varus femoral stem position respectively. All patients gave written consent to be a part of this study.

Preoperatively, radiological assessment of the femoral head size is done by comparing it to the opposite side. Surgeries were performed under combined spinal and epidural anaesthesia. Patient was positioned in lateral decubitus with fractured side up (Figure 1). Anterolateral approach to hip joint was carried out andthe anterior capsule of the hip joint was incised in a T-shaped fashion by cutting the attachment of the capsule to the acetabulum. The head of the femur was extracted, using the skid after doing osteotomy of the neck (Figure 2). Intraoperatively, the size of excised head of femur was measured using templates and trialled with prosthesis (Figure 3). After adequate preparation, the selected size of pre-sterilized (gamma irradiated) uncemented bipolar prosthesis was press fitted into the prepared medullary canal, ensuring a snugly fit prosthesis in $15^{\circ}$ of anteversion and without any movement between the shaft \& stem. Movements of the limb at the hip joint was then checked for any loosening at the head-acetabular interface or at the shaft-stem interface. Drains was kept post-operatively. The suturing technique involved layer by layer closure till the skin. Sterile dressing subsequently followed the closure of the wound.
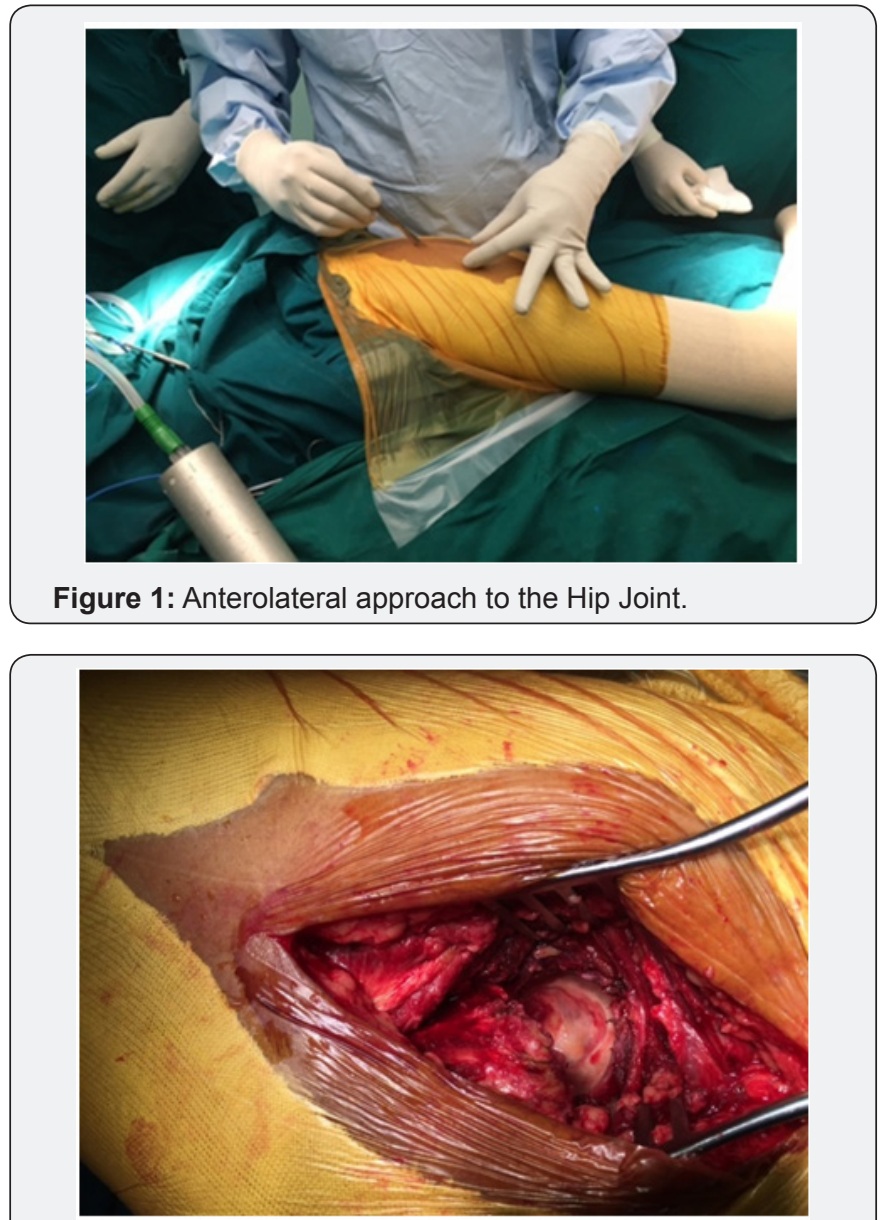

Figure 2: Femoral head in situ.

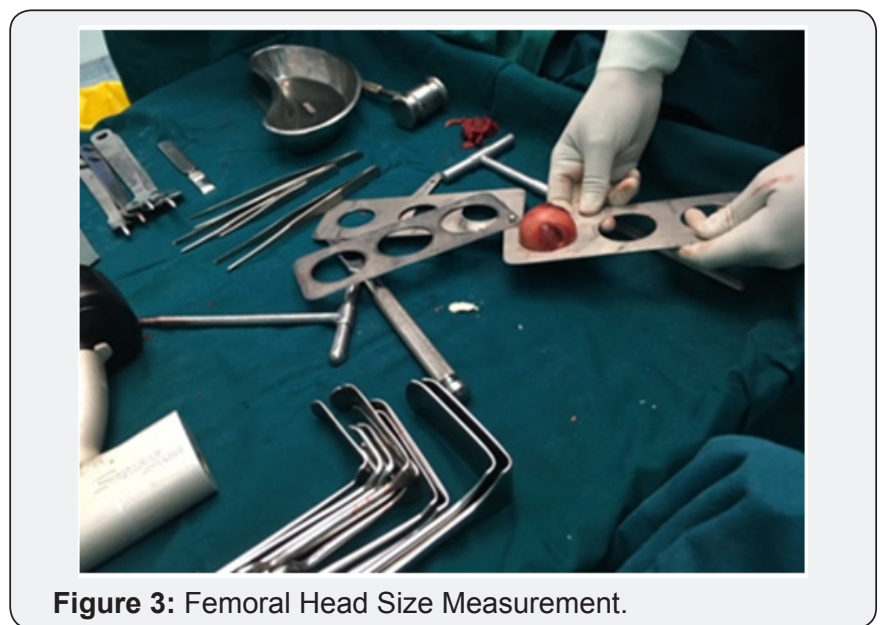

Postoperatively, the primary operative site was checked 48 to 72 hours after surgery and drain removed. Physiotherapy started on first post-operative day and mobilization with walker was done by $4^{\text {th }}$ day. Check radiograph was taken after 48 hours and limb length discrepancies were assessed, both clinically as well as radiologically. Patient was asked to follow-up after 14 days for suture removal and then subsequently at 6 weeks, 3 months and 6 months. Harris hip score was recorded for range of motion at each visit from $6^{\text {th }}$ week. Evaluation of positioning of 


\section{Juniper Online Journal of Case Studies}

the tip of the stem using conventional AP X-ray of Hip joint was evaluated. A line was drawn parallel with the prosthesis stem until it angled with the anatomical axis of the femur. Alignment was divided into three groups: valgus alignment ( $>3^{\circ}$ valgus), neutral $\left(3^{\circ}\right.$ varus to $3^{\circ}$ valgus) and varus ( $>3^{\circ}$ varus). Thus, patients were divided into 3 groups depending on stem position.

\section{Statistical Analysis}

Statistical data analysis was conducted using SPSS 18.0. Student $t$ test and chi square test were used to compare the level of significance with $\mathrm{p}$ value $\leq 0.05$ considered as statistically significant.

\section{Result}

In our study of 32 patients undergoing uncemented bipolar hemiarthroplasty, the mean age of patients in Valgus Group was

Table 1: Age distribution between two study groups.

\begin{tabular}{|c|c|c|c|c|c|}
\hline \multirow{2}{*}{ Age Group (Years) } & \multicolumn{2}{|c|}{ Valgus Group (n=16) } & \multicolumn{2}{c|}{ Varus Group (n=16) } & $\begin{array}{c}\text { P-value [Inter- } \\
\text { Group] }\end{array}$ \\
\cline { 2 - 6 } & $\mathbf{n}$ & $\mathbf{\%}$ & $\mathbf{n}$ & 12.5 & 0.312 \\
\hline $50.0-59.0$ & 3 & 18.8 & 7 & 43.8 & \\
\hline $60.0-69.0$ & 10 & 62.5 & 7 & 43.8 & \\
\hline$>70.0$ & 3 & 18.8 & 16 & 100 & \\
\hline Total & 16 & 100 & & \\
\hline
\end{tabular}

Table 2: Mode of Injury among varus and valgus group.

\begin{tabular}{|c|c|c|c|c|c|}
\hline \multirow{2}{*}{ Mode of Injury } & \multicolumn{2}{|c|}{ Valgus Group (n=16) } & \multicolumn{2}{c|}{ Varus Group (n=16) } & \multirow{2}{*}{$\begin{array}{c}\text { P-value [Inter- } \\
\text { Group] }\end{array}$} \\
\cline { 2 - 5 } & $\mathbf{n}$ & $\mathbf{0}$ & $\mathbf{n}$ & 18.8 & 0.999 \\
\hline Road Traffic Accident & 4 & 25 & 13 & 81.2 & \\
\hline Slip and Fall & 12 & 75 & 16 & 100 & \\
\hline Total & 16 & 100 & 3 & \\
\hline
\end{tabular}

Table 3: Comparing 6-months mean functional outcome measures in terms of Range of Motion (ROM) and Harris hip score.

\begin{tabular}{|c|c|c|c|c|c|}
\hline \multirow{2}{*}{ Outcome Measures } & \multicolumn{2}{|c|}{ Valgus Group (n=16) } & \multicolumn{2}{c|}{ Varus Group (n=16) } & $\begin{array}{c}\text { P-value [Inter- } \\
\text { Group] }\end{array}$ \\
\cline { 2 - 5 } & Mean & SD & Mean & 6 & 0.999 \\
\hline Flexion (Deg) & 104.4 & 4.8 & 104.4 & 3.8 & 0.999 \\
\hline $\begin{array}{c}\text { External Rotation } \\
\text { (Deg) }\end{array}$ & 20.9 & 3.8 & 20.9 & 3.8 & 0.807 \\
\hline Abduction (Deg) & 26.3 & 3.4 & 25.9 & 4.2 & 0.999 \\
\hline Adduction (Deg) & 15.9 & 3.8 & 15.9 & 5.8 & 0.418 \\
\hline Harris Hip Score & 89.2 & 2.7 & 87.8 & & \multirow{2}{*}{0.9} \\
\hline
\end{tabular}

Table 4: Comparison of overall result.

\begin{tabular}{|c|c|c|c|c|c|}
\hline \multirow{2}{*}{ Overall Result } & \multicolumn{2}{|c|}{ Valgus Group (n=16) } & \multicolumn{2}{c|}{ Varus Group (n=16) } & $\begin{array}{c}\text { P-value [Inter- } \\
\text { Group] }\end{array}$ \\
\cline { 2 - 5 } & $\mathbf{n}$ & $\mathbf{0}$ & 3 & 18.8 & $0.191 \mathrm{NS}$ \\
\hline Fair & 0 & 0 & 5 & 31.3 & \\
\hline Good & 6 & 37.5 & 8 & 50 & \\
\hline Excellent & 10 & 62.5 & 16 & 100 & \\
\hline Total & 16 & 100 & & \\
\hline
\end{tabular}




\section{Discussion}

Fractures of the femoral neck are a common problem in the elderly, after a trivial fall due to osteoporosis and is more common in females than males due to post-menopausal osteoporosis. The number of intracapsular fractures are increasing due to increase in life expectancy linked to advances in the medical field. The treatment modalities for such fractures has evolved from a simple Austin-Moore prosthesis to a complicated total hip replacement. A thorough understanding of the needs of the patient, condition of the joint along with the financial aspect of the surgeries can help the orthopaedic surgeon chose the appropriate procedure for the patient.

In our study, the average age was 65.95 years with a range of 58-85 years. Equal number of male and female patients were represented in the study. In addition, there was equal distribution between varus and valgus group. Past studies have shown that more female patients were part of the study in comparison to male due to post-menopausal osteoporosis. This was observed in series by Rogmark et al. [8] which had a female patient percentage of 79, 73.4\% in Anders Enocson et al. [9] and $74 \%$ in series by Figved et al. [10]. Moreover, our mean Harris hip score was comparable to other studies previously published (Table 5).

Table 5: Mean Harris Hip Score between various studies.

\begin{tabular}{|c|c|}
\hline Study & Mean HHS \\
\hline Our study & 88.5 \\
\hline Varus & 87.8 \\
\hline Valgus & 89.2 \\
\hline Figved [10] & 78.9 \\
\hline Giliberty [11] & 87 \\
\hline Krishnan [12] & 74.7 \\
\hline Rajendra anappa [13] & 83.5 \\
\hline Ellen langslet [14] & 79.1 \\
\hline
\end{tabular}

None of our patients develop thrombo-embolic episode, limb length discrepancy, infection, dislocation and peri-prosthetic fractures which was observed in other studies $[9,10]$. The limitation in this study was shorter duration of follow up.

\section{Conclusion}

We conclude that hemiarthroplasty using uncemented bipolar prosthesis is a good procedure for the elderly and provides early rehabilitation. There is no statistical difference between Harris hip score of varus and valgus group.

\section{References}

1. Johnell 0, Kanis J (2005) Epidemiology of osteoporotic fractures. Osteoporos Int 16 Suppl 2: S3-S7.

2. Sambrook P, Cooper C (2006) Osteoporosis. Lancet 367(9527): 20102018.

3. Mark SF (1994) Current concepts review. Intracapsular fracture of hip. JBJS 76(1): 129-135.

4. Johnson EO, Soultanis K, Soucacos PN (2004) Vascular anatomy and microcirculation of skeletal zones vulnerable to osteonecrosis. Orthop Clin North Am 35(3): 285-291.

5. Lavelle DG (2008) Fractures and dislocations of the hip. In: Canale ST, Beaty JH (eds), Campbell's operative Orthopaedics. (11 ${ }^{\text {th }}$ Edn), Mosby, Penslyvania, USA, pp. 3271-3285.

6. Keating J (2010) Femoral neck fractures. In: Bucholz RW, et al. (Eds.), Rockwood and Green's Fractures in Adults. ( $7^{\text {th }}$ edn), Lippincott Williams and Wilkins: Philadelphia, USA, pp. 1561-1596.

7. Parker MI, Pryor G, Gurusamy K (2010) Cemented versus uncemented hemiarthroplasty for intracapsular hip fractures a randomised controlled trial in 400 patients. J Bone \& Joint Surgery Br 92(1): 116122.

8. Rogmark C, Carlsson A, Johnell O, Sernbo I (2002) A prospective randomized trial of internal fixation versus arthroplasty for displaced fractures of neck of femur. Functional outcome for 450 patients at two years. J Bone Joint Surg Br 84(2): 183-188.

9. Enocson A, Hedbeck CJ, Törnkvist H, Tidermark J, Lapidus LJ (2012) Unipolar verses bipolar Exeter hip hemiarthroplasty: a prospective cohort study on 830 consecutive hips in patients with femoral neck fractures. Intl Orthop 36(4): 711-717.

10. Figved W, Opland V, Frihagen F, Jervidalo T, Madsen JE, et al. (2009) Cemented versus Uncemented hemiarthroplasty for displaced femoral neck fractures. Clin Orthop Relat Res 467(9): 2426-2435.

11. Giliberty RP (1983) Hemiarthroplasty of the hip using low-friction bipolar endoprosthesis. Clin Orthop Relat Res 175: 86-72.

12. H Krishnan, TR Yoon, KS Park (2010) Bipolar hemiarthroplasty in elderly patients presenting with displaced intracapsular femoral neck fractures - A comparison of cemented and uncemented prosthesis placement. Malaysian Orthopaedic Journal 4(1): 26-31.

13. Annappa R, Jhamaria NL, Suresh PK (2014) Cemented or uncemented hemiarthroplasty for displaced intra-capsular femoral neck fractures. Int J Biomed Adv Res 5(9): 432-434.

14. Langslet E, Frihagen F, Opland V, Madsen JE, Nordsletten L, et al. (2014) Cemented versus uncemented hemiarthroplasty for displaced femoral neck fractures: 5-year follow up of a randomized trial. Clin Orthop Relat Res 472(4): 1291-1299. 


\section{Your next submission with Juniper Publishers} will reach you the below assets

- Quality Editorial service

- Swift Peer Review

- Reprints availability

- E-prints Service

- Manuscript Podcast for convenient understanding

- Global attainment for your research

- Manuscript accessibility in different formats ( Pdf, E-pub, Full Text, Audio)

- Unceasing customer service

Track the below URL for one-step submission https://juniperpublishers.com/online-submission.php 